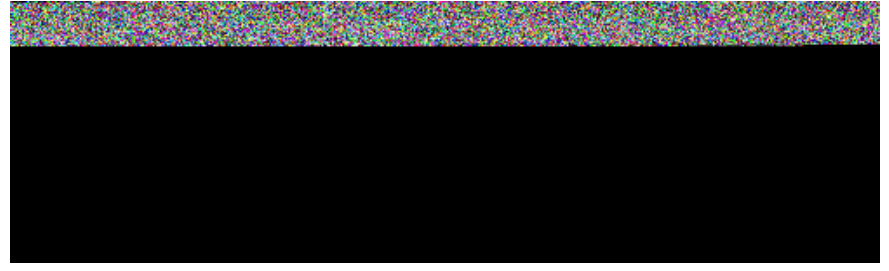

This information is current as of April 26, 2023.

\title{
Normal Sagittal and Coronal Suture Widths by Using CT Imaging
}

L.A. Mitchell, C.A. Kitley, T.L. Armitage, M.V. Krasnokutsky and V.J. Rooks

AJNR Am J Neuroradiol 2011, 32 (10) 1801-1805

doi: https://doi.org/10.3174/ajnr.A2673

http://www.ajnr.org/content/32/10/1801 


\section{ORIGINAL RESEARCH \\ Normal Sagittal and Coronal Suture Widths by Using CT Imaging}

\author{
L.A. Mitchell \\ C.A. Kitley \\ T.L. Armitage \\ M.V. Krasnokutsky \\ V.J. Rooks
}

\begin{abstract}
BACKGROUND AND PURPOSE: Pediatric cranial sutures are often evaluated for abnormal diastasis upon presentation to the emergency department after trauma or during a neurologic consultation; however, few normative data for CT measurements exist. This study establishes normal means for the sagittal and coronal suture widths during the first year of life by using CT.
\end{abstract}

MATERIALS AND METHODS: The sagittal suture and bilateral coronal sutures were evaluated for 483 patients, ages 1 day to 395 days collected retrospectively from electronic medical records. Histograms as well as normality and boxplots were used to view the distribution of the data. An analysis of variance was performed for each suture measured by using month of age as the independent class variable.

RESULTS: The average proximal suture widths for the sagittal and coronal sutures at zero months of age were $5.0 \pm 0.2$ and $2.5 \pm 0.1 \mathrm{~mm}$, respectively. From zero to 1 month of age, these sutures narrowed significantly to $2.4 \pm 0.1$ and $1.3 \pm 0.1 \mathrm{~mm}$, respectively. From 1 to 12 months of age, sutures narrowed gradually. The proximal coronal suture widths showed a significant reduction from 1 month to 12 months $(1.3 \pm 0.1-0.8 \pm 0.1 \mathrm{~mm})$.

CoNCLUSIONS: The normative values for suture widths established by CT scan among this large population may be used to assess the infant calvaria for suture diastasis.

ABBREVIATION: ICC = intraclass correlation coefficient
$\mathbf{T}$ he United States has seen a recent rise in the number of emergency department visits from 352.8 to 390.5 per 1000 persons over the time span of 1997-2007. ${ }^{1}$ This trend also is reflected in the pediatric population, ${ }^{2}$ which, along with difficulty obtaining a good history, lowers the threshold for the emergency department physician to image pediatric patients. In 2008, the American College of Radiology produced an updated version of its Appropriateness Criteria for head trauma, which provides both the clinician and the radiologist with guidelines for imaging in the setting of acute head injury. ${ }^{3,4} \mathrm{CT}$ is considered appropriate in the evaluation of pediatric patients presenting with seizures, trauma, or the concern for nonaccidental trauma.

Pediatric head trauma is a common presentation for emergency department and acute care clinic visits. ${ }^{5}$ More than 1.5 million head injuries occur annually in the United States, resulting in approximately 300,000 pediatric hospitalizations. ${ }^{6}$ A key component of the work-up for infants who have increased somnolence, a large hematoma, loss of consciousness, or change in behavior is an imaging evaluation of the head. As

Received January 19, 2011; accepted after revision March 18.

From the Department of Radiology (L.A.M., V.J.R.), Tripler Army Medical Center, Honolulu, Hawaii; Department of Radiology (C.A.K., M.V.K.), Madigan Army Medical Center, Tacoma, Washington; Statistical Consultant (T.L.A.), Clovis, New Mexico; and Department of Radiology and Radiological Sciences (M.V.K., V.J.R.), Uniformed Services University of the Health Sciences, Bethesda, Maryland.

This work was previously presented in part at: 95th Scientific Assembly and Annual Meeting of the Radiological Society of North America, November 29-December 4, 2009, Chicago, Illinois (LL-PD4254-D08) and 48th Annual Meeting of the American Society of Neuroradiology, May 15-20, 2010, Boston, Massachusetts.

Disclaimer: The views expressed in this abstract/manuscript are those of the author(s) and do not reflect the official policy or position of the Department of the Army, Department of Defense, or the U.S. Government.

Please address correspondence to Lex A. Mitchell, Department of Radiology, MCHK-DR, Tripler Army Medical Center, 1 Jarrett White Rd, Honolulu, HI 96589; e-mail: lex.a.mitchell@us.army.mil

http://dx.doi.org/10.3174/ajnr.A2673 imaging technology has advanced, so has the evaluation of the acutely injured head. Henderson and Sherman ${ }^{7}$ were among the first to assess neonate sutures. They evaluated 100 neonate infants by radiography, demonstrating a large variation in the coronal and sagittal suture widths. ${ }^{7}$ Erasmie and Ringertz ${ }^{8}$ provided numerical data from imaging to assess sutural diastasis; however, conventional radiology does not provide an assessment of the intracranial anatomy nor is it indicated for most patients who are at moderate to high risk for intracranial pathology. ${ }^{6}$ As sonography technology advanced, sutural appearance and intracranial distances were assessed to determine normality. ${ }^{9}$ In the acute setting, however, sonography is not the preferred method of assessing the pediatric head due to variability between ultrasonographers, ${ }^{9}$ ultrasonographer availability, and limited overall assessment of intracranial contents.

CT scanning affords uncontested superior evaluation of intracranial contents and morphology in comparison with conventional radiography ${ }^{10}$ and sonography in the acute setting. ${ }^{6}$ Furthermore, the American College of Radiology has recommended that if a patient has neurologic symptoms and there is suspicion of nonaccidental trauma, a noncontrast CT of the head should be performed. ${ }^{4,11}$ As part of the morphologic evaluation in the acute setting, a close evaluation of the sutures is performed to assess for fracture, ${ }^{12}$ diastasis, ${ }^{11}$ or early closure.

There is scant literature describing normal suture widths among the infant population. Although case reports of cephalomegaly predominate in the literature, few studies have undertaken a systematic analysis to quantify normal suture widths based on CT. ${ }^{13,14}$ To date, radiologists have largely relied on gestalt and experience to assess sutures for pathology based on knowledge that there may be a large variation in suture width during the first month of life with sutures eventually closing at $22-24$ years of age. ${ }^{15}$ 


\begin{tabular}{lccr}
\hline \multicolumn{2}{l}{ Table 1: Patient demographics } & & \\
\hline $\begin{array}{l}\text { Age Group } \\
\text { (mo) }\end{array}$ & $N$ & $\begin{array}{c}\text { Female } \\
(\%)\end{array}$ & $\begin{array}{c}\text { Mean (SD) } \\
\text { Age (wk) }\end{array}$ \\
\hline 0 & 156 & 60 & $1.6(1.3)$ \\
1 & 72 & 40 & $6.2(1.0)$ \\
2 & 87 & 50 & $10.8(1.3)$ \\
3 & 64 & 25 & $15.2(1.2)$ \\
6 & 77 & 37 & $27.7(1.2)$ \\
12 & 27 & 16 & $54.2(1.4)$ \\
\hline
\end{tabular}

Table 2: Imaging indication (by percentage)

\begin{tabular}{lrrrrrr}
\hline & \multicolumn{6}{c}{ Age (mo) } \\
\cline { 2 - 7 } Indication & \multicolumn{1}{c}{1} & \multicolumn{1}{c}{ ( } & \multicolumn{1}{c}{3} & 6 & 12 \\
\hline Trauma & 33 & 59 & 55 & 71 & 54 & 53 \\
New onset seizure & 25 & 13 & 12 & 6 & 7 & 13 \\
Rule out mass & 3 & 4 & 13 & 12 & 20 & 22 \\
Infection & 12 & 4 & 4 & 4 & 5 & 3 \\
Rule out congenital/genetic abnormality $^{\text {Other }}{ }^{\text {a }}$ & 11 & 1 & 3 & 3 & 6 & 0 \\
\hline
\end{tabular}

a Other justifications included but not limited to apnea and questionable intracranial hemorrhage.

Given the lack of standard normal values on CT, this study was proposed to assist the interpreting radiologist in diagnosing cranial suture abnormalities. The mean values for suture widths based upon the CT scans in this large data base of normal CT studies may be helpful in assessing the infant calvaria for suture diastasis.

\section{Materials and Methods}

\section{Patients}

The study protocol was approved by the Human Use Committee at 2 different institutions. Investigators adhered to the policies for protection of human subjects as prescribed in 45 CFR 46 and provision 32CFR219.110. A review of CT imaging reports on the PACS identified patients with no acute intracranial pathology or a normal CT of the head; the study included head CTs conducted among patients 1 year of age or younger during the period January 1, 1994, through December 31,2008 . All known premature infants were excluded from the dataset. The study sample included 483 patients between 1 and 395 days of age (mean, 96 days). The CT data available included 966 sagittal suture evaluations and 1932 coronal suture evaluations. Among the selected patients, 251 were male and 232 female, with a disproportionate representation of the neonate cohorts as reflected by the low mean months of age (Table 1) but with similar histories across the age groups (Table 2). Age, in days, was abstracted from the radiologic information system. The age in weeks was calculated by dividing the provided days of life by 7 , and the month of life was determined based on a 30-day average month, with the assigned month representing the last complete month of life. Patients were subsequently assigned into the following 6 age groups for analysis: $0,1,2,3,6$, and 12 months.

\section{CT Imaging Techniques}

The sagittal suture and bilateral coronal sutures were evaluated on axial imaging with a 5-mm section interval by using an average kilovolt peak of 120 and product of the tube current and the exposure time of 120 , standard algorithm, and average window/level values of 3077 and 570 , respectively. ${ }^{10}$ Imaging was performed on a 16 -detector row, 8-detector row, or 4-detector row CT scanner (GE Medical Systems, Milwaukee, Wisconsin).

\section{CT Imaging Analysis}

The sagittal suture and bilateral coronal sutures were evaluated on axial imaging by using a measurement selection point similar to Erasmie and Ringertz ${ }^{8}$ and electronic calipers measuring distances along the inner margin of the suture. All suture width measurements were made in relation to the anterior fontanelle, confirmed on cross-referenced lateral scout images, and reviewed by 2 senior board-certified radiologists with certificates of added qualification. Values of sutural width were obtained in the proximal one-third of the sagittal (Figs $1 A$ and $2 A$ ) and bilateral coronal sutures (Figs $1 B$ and $2 B$ ) as well as the distal two-thirds of each suture (Fig $1 A-, B$ ). Evaluation of interdigitated sutures was performed by obtaining 3 different measurements, and the mean was used as the suture width. Suture width measurements were checked for consistency by blinded peer-review analysis.

\section{Statistics}

Descriptive statistics included histograms, scatterplots, and boxplots to view the distribution of the suture width data across the population by age of the patient. Data were analyzed by analysis of variance to compare means to evaluate differences by age group. A Bonferroni post hoc evaluation was used to compare adjusted means, by using SEs, to determine significant difference between age groups. Significant variation between right and left coronal sutures was analyzed by using a paired $t$ test. The significance level for all comparisons was .05 . Interrater reliability was assessed by calculating ICCs. Ten examinations were selected at random, and the coronal and sagittal sutures reviewed by the 2 senior radiologists. ICCs were calculated to assess agreement of measurements obtained at the proximal sagittal and coronal sutures as well as the distal sagittal and coronal sutures.

\section{Results}

\section{Assessment of Sagittal Suture Width}

The mean proximal sagittal suture width at 0 months of age was $5.0 \pm 0.2 \mathrm{~mm}$ (Fig $3 A$ ). In comparison to neonates, the mean proximal suture width of 1 -month-olds was approximately half $(2.4 \pm 0.1 \mathrm{~mm} ; P<.001)$. In comparison with 1 -month-olds, infants 6 months of age had significantly narrower mean suture widths $(P<.001)$ and likewise for infants 12 months of age compared with 1 -month-olds $(P<.001$; Fig $3 A$ and Table 3). Other month-by-month comparisons between $2,3,6$, and 12 months did not reach significance.

The mean distal sagittal suture width at 0 months of age was $4.6 \pm 0.2 \mathrm{~mm}$ (Fig $3 B$ ). In comparison to neonates, the mean distal sagittal suture width of 1 -month-olds was approximately $45 \%$ narrower $(2.6 \pm 0.1 \mathrm{~mm} ; P<.001)$. Compared with 1 -month-olds, the mean suture width of the 3-montholds was significantly narrower as was that of 6-month-olds and 12 -month-olds $(P<.0001)$. The decrease in suture width did not continue to reach statistical significance for other month-by-month comparisons with the exception of 2 months and 12 months $(P<.028$; Fig $3 B$ and Table 3$)$.

\section{Assessment of Coronal Suture Width}

The right and left coronal sutures closed at the same rate as reflected by mean widths that were statistically indistinguishable from each other at all time points measured (Table 3 and 

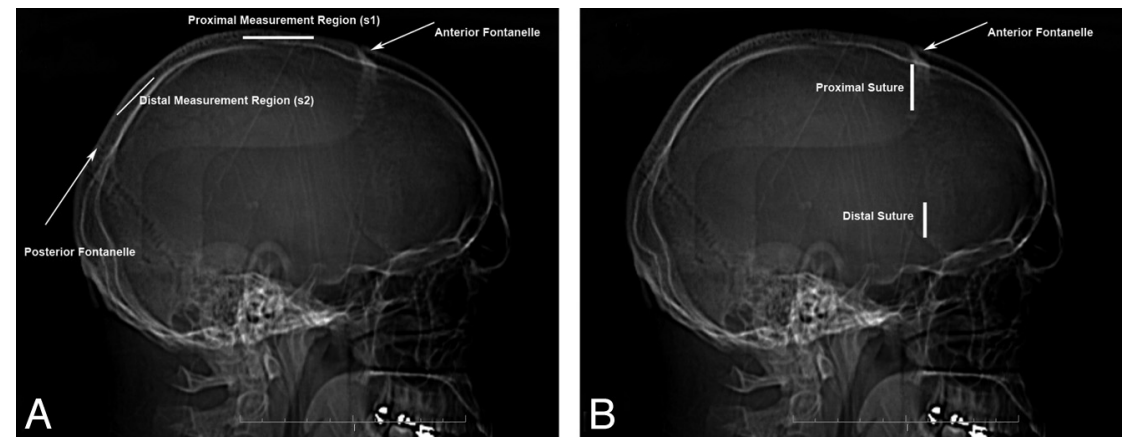

Fig 1. Scout suture evaluation. $A$, Lateral scout image from CT scan of a young child demonstrating the location of proximal (s1, solid bar) and distal (s2, solid bar) sagittal suture measurements. Measurements were obtained at a minimum distance of $5 \mathrm{~mm}$ from the associated fontanelle. $B$, Lateral scout image from CT scan of a young child demonstrating the location of proximal and distal measurements (solid bars). Measurements were obtained at a minimum distance of 5 mm from the anterior fontanelle and the sphenosquamous suture.
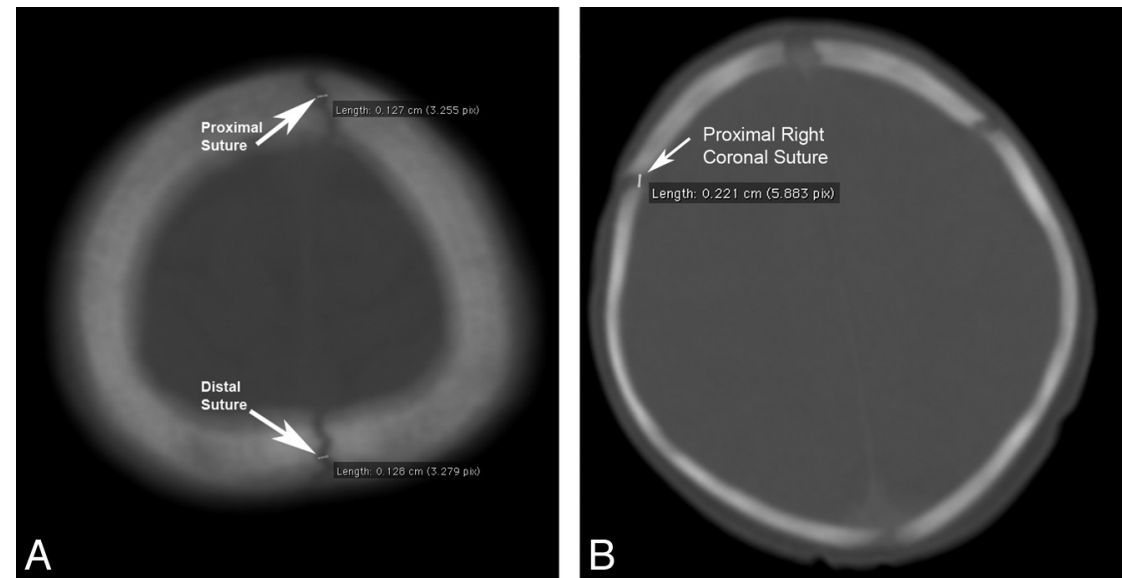

Fig 2. Axial suture evaluation. Bone algorithm axial CT images of a 6 -month-old head $(A)$ at 5 -mm intervals, demonstrating sample measurements of the sagittal suture and of a 0 -monthold head $(B)$ at 5-mm intervals, demonstrating sample measurements of the coronal suture.

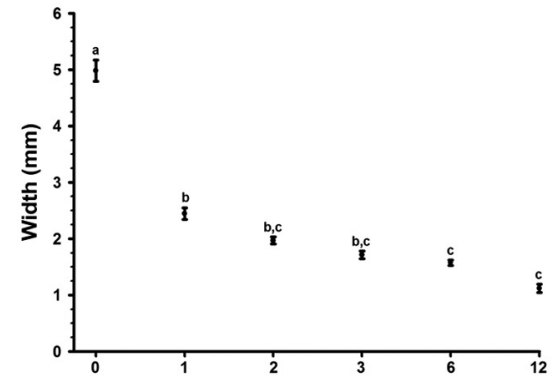

A

Age (months)

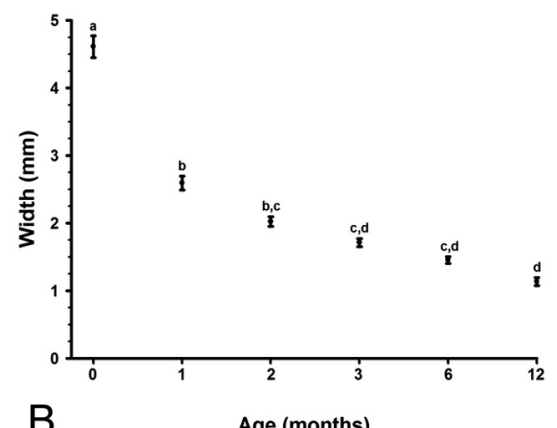

B Age (months)

Fig 3. Sagittal suture width. Age variation of the proximal $(A)$ and distal $(B)$ sagittal suture width over a 1-year period. Data are represented as means \pm SE $(n=27-156)$. Means with different superscripts $(a, b, c, d)$ are statistically different $(P<.05)$.

Fig $4 A,-B)$. In contrast, there was significant difference between mean proximal coronal suture width at 0 months of age and 1 month of age, $2.5 \pm 0.1$ and $1.3 \pm 0.1 \mathrm{~mm}$, respectively $(P<0.001$; Fig $5 A)$. Unlike the sagittal suture, there was no significant reduction in the mean proximal coronal suture width between 1 and 12 months of age $(1.3 \pm 0.1$ versus $0.8 \pm$ $0.1 \mathrm{~mm}$; Fig $5 A$ ).

The mean distal coronal suture widths at zero months of age was $1.5 \pm 0.1 \mathrm{~mm}$ (Fig $5 B$ ). By the first month of age, the mean distal suture width had decreased significantly to $1.1 \pm$ $0.1 \mathrm{~mm}(P<.001)$. There was no statistically significant reduction in the suture width between 1 and 3 month of age. The large number of coronal CT evaluations supported findings of statistical significance by 12 months of age versus $1,2,3$, and 6 months $(P=.001,0.002,0.001$, and 0.031 , respectively; Fig 5B).

\section{Comparison with Sonography}

Proximal sagittal and coronal suture widths were compared with previously published sonography results evaluating the sagittal and coronal sutures. ${ }^{9}$ The proximal sagittal suture measured $5.0 \pm 0.2 \mathrm{~mm}$ by CT at 0 months of age, whereas the measured range by sonography was approximately $0.9-1.4$ $\mathrm{mm}$. At 1 month, the proximal sagittal suture measured $2.5 \pm$ $0.1 \mathrm{~mm}$ by CT, whereas the range by sonography was approximately $0.6-1.2 \mathrm{~mm}$; at 2 months the proximal sagittal suture 


\begin{tabular}{|c|c|c|c|c|c|c|}
\hline \multirow{2}{*}{$\begin{array}{l}\text { Age } \\
\text { (mo) }\end{array}$} & \multicolumn{2}{|c|}{ Sagittal Suture (mm) } & \multicolumn{2}{|c|}{ Right Coronal Suture (mm) } & \multicolumn{2}{|c|}{ Left Coronal Suture (mm) } \\
\hline & Proximal & Distal & Proximal & Distal & Proximal & Distal \\
\hline 0 & $5.0 \pm 0.2^{\mathrm{a}}$ & $4.6 \pm 0.2^{\mathrm{a}}$ & $2.5 \pm 0.1^{\mathrm{a}}$ & $1.5 \pm 0.1^{\mathrm{a}}$ & $2.4 \pm 0.1^{\mathrm{a}}$ & $1.5 \pm 0.1^{\mathrm{a}}$ \\
\hline 1 & $2.4 \pm 0.1^{b}$ & $2.6 \pm 0.1^{b}$ & $1.3 \pm 0.1^{b}$ & $1.1 \pm 0.1^{\mathrm{b}}$ & $1.3 \pm 0.1^{b}$ & $1.1 \pm 0.1^{b}$ \\
\hline 2 & $2.0 \pm 0.2^{b, c}$ & $2.0 \pm 0.1^{b, c}$ & $1.2 \pm 0.1^{b}$ & $0.9 \pm 0.1^{\mathrm{b}, \mathrm{c}}$ & $1.2 \pm 0.1^{b}$ & $0.9 \pm 0.1^{b, c}$ \\
\hline 3 & $1.7 \pm 0.1^{\mathrm{b}, \mathrm{c}}$ & $1.7 \pm 0.1^{c, d}$ & $1.1 \pm 0.1^{b}$ & $1.0 \pm 0.1^{\mathrm{b}, \mathrm{c}}$ & $1.2 \pm 0.1^{b}$ & $1.0 \pm 0.1^{\mathrm{b}, \mathrm{c}}$ \\
\hline 6 & $1.6 \pm 0.1^{c}$ & $1.5 \pm 0.1^{c, d}$ & $1.1 \pm 0.1^{b}$ & $0.8 \pm 0.1^{\mathrm{b}, \mathrm{c}}$ & $1.0 \pm 0.1^{b}$ & $0.8 \pm 0.1^{b, c}$ \\
\hline 12 & $1.1 \pm 0.1^{\mathrm{c}}$ & $1.1 \pm 0.1^{d}$ & $0.8 \pm 0.1^{b}$ & $0.5 \pm 0.1^{d}$ & $0.9 \pm 0.1^{b}$ & $0.5 \pm 0.1^{d}$ \\
\hline
\end{tabular}

Note:-Data are presented as mean \pm SE. Means with different superscripts $(a, b, c, d)$ are statistically different $(P<.05)$ at the specified location.
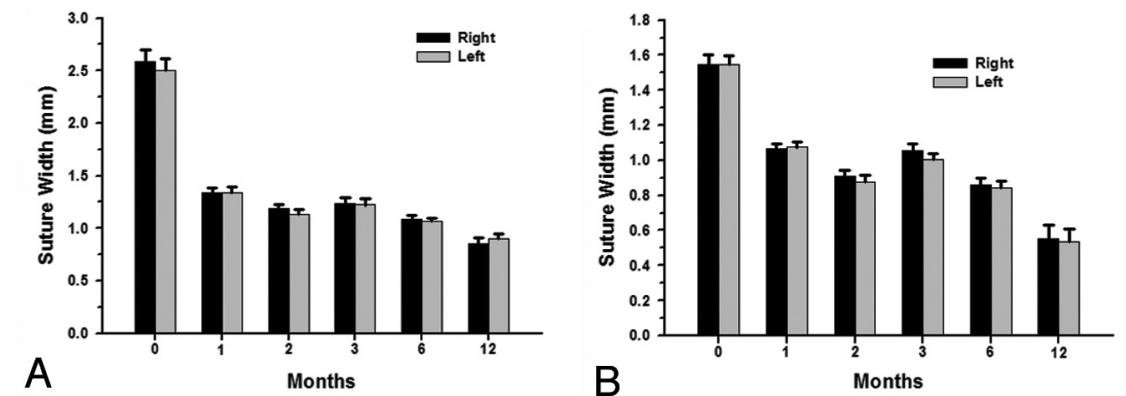

Fig 4. Comparison of the right and left proximal $(A)$ and distal $(B)$ coronal suture widths over a 1-year-period. At each time point, there was no difference between the right and left coronal suture. Data are represented as means $\pm \mathrm{SE}(n=27-156)$.
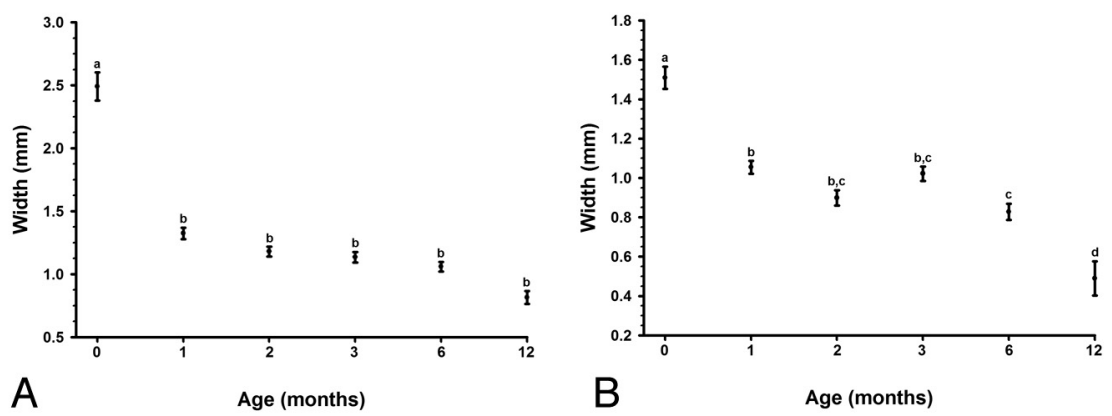

Fig 5. Age variation of the proximal $(A)$ and distal $(B)$ coronal suture width over a 1-year period. Data are represented as means $\pm S E(n=27-156)$. Means with different superscripts $(a, b, c, d)$ are statistically different $(P<.05)$.

measured on CT was $2.0 \pm 0.1 \mathrm{~mm}$, whereas the range by sonography was approximately $0.5-1.7 \mathrm{~mm}$. At 3 months, measured CT width of the proximal sagittal suture was $1.7 \pm$ $0.1 \mathrm{~mm}$, and sonography was approximately $0.5-1.7 \mathrm{~mm}$.

The proximal coronal suture measured $2.5 \pm 0.1 \mathrm{~mm}$ by $\mathrm{CT}$ at 0 months of age, whereas the range by sonography was approximately $0.9-1.5 \mathrm{~mm}$. At 1 month, the proximal coronal suture width measurement by CT was $1.3 \pm 0.1 \mathrm{~mm}$, whereas sonography was approximately $0.5-2.1 \mathrm{~mm}$. At 2 months, proximal coronal suture widths measured $1.2 \pm 0.1 \mathrm{~mm}$ on CT, whereas sonography was approximately $0.4-1.5 \mathrm{~mm}$. At 3 months, the proximal coronal suture measured $1.1 \pm 0.1$ $\mathrm{mm}$ on $\mathrm{CT}$, whereas the range by sonography was approximately $0.4-2.9 \mathrm{~mm}$. No previously reported data were found to measure ultrasound suture widths for infants ages 6-12 months.

\section{Assessment of Interrater Reliability}

ICCs ranged from 0.88 to 0.99 , indicating agreement between the 2 senior radiologists.

\section{Discussion}

The United States has seen a rise in the use of emergency departments for pediatric evaluation. ${ }^{2} \mathrm{~W}$ ith this rise in visits has come a concomitant rise in the number of cross-sectional imaging studies performed. There are a varied number of reasons for neonates and infants to undergo CT imaging of the head; however, the overwhelming reason is trauma both nationally ${ }^{1,2}$ and in our population (Table 2 ). The CT evaluation of the pediatric head for hemorrhage from either accidental or nonaccidental trauma can be performed quickly, and readily answers the question. However, where there is concern for sutural fracture or diastasis, the assessment has historically relied on the experience of the reviewing radiologist.

This study expands on the evaluation of sutures initially discussed by Erasmie and Ringertz. ${ }^{8}$ Our data delineate a CT table for sagittal and coronal suture widths throughout the first year of life. These data correlated with previously reported sonography measurements of suture width at 2 and 3 months. ${ }^{9}$ Although our CT sutural width measurements were larger at 0 months of age and 1 month of age than the sonog- 
raphy data, this variation in suture width may be secondary to our larger sample size and or including a fibrous portion of the suture. No additional studies have been found to date to compare older infant (ages 6-12 months) suture widths, probably due to rapidly closing suture width.

We recognize that the current study has limitations that should be noted. First, premature infants may have been included in the sample population. The data base query yielded results based upon patient age but did not take into consideration the gestational age of the infant at the time of birth. Although we excluded all known premature infants, the prematurity may not have been indicated in the charts of infants adopted or those new to our health care system. It is possible that the inclusion of premature infants may skew the measurements at 0 and 1 month of age but probably did not affect results of the older age groups. Also, the amount of skew was probably offset by the larger sample sizes in the younger age groups, which presumably included mostly full-term infants.

Second, the patients' medical charts were not reviewed to determine whether a patient who was given the results of normal or no acute intracranial pathology might have later developed complications. We feel this potential limitation is minimized in the closed community from which the sample was drawn. These patients would have had follow-up imaging that also would have appeared in our data base query, or the primary care provider would have notified the radiologists if further imaging were needed. None of the patients in this study had such follow-up imaging or notification.

Also, there was a slight male predominance in the study population, and we did not separate patients by sex. Previous anthropologic studies have suggested a slight increase in suture width among the adult male population versus the adult female population ${ }^{16}$; however, an equivalent number of studies did not reach the same conclusion. ${ }^{17}$ Results also were not stratified by ethnicity because previous studies have not found this effect to be statistically significant. ${ }^{16,18-20}$

Finally, the authors recognize the inherent limitation of assessing sutures that may be smaller than the section thickness of the acquired images. Reviewing both the transverse images and the cross-referenced scout images mitigated the section thickness limitation by allowing the authors to confirm that the location of measurement was representative.

In summary, CT measurements of mean suture widths decrease rapidly in the first year of life. The most dramatic closure occurs during the first month of life for all measurement points followed by gradual decrease in width during the remainder of the first year of life was reached. Statistical significance for closure of all suture measurement points, during the first month of life. Based on these data, we developed normative values for the coronal and sagittal sutures on CT during the first 12 months of life. The data allow extrapolation of normal values for the intervening months. These results cor- related well with prior reports of sonography measurements verifying this method of analysis. ${ }^{8}$

This study is the first to derive suture widths on CT across a broad population of infants reflecting the most common technology used today. The suture widths listed by month here afford radiologists a quick and reliable means of assessing a patient's suture width against normative values for CT.

\section{Conclusions}

The normative values for suture widths established by CT scan among this large population may be used to assess the infant calvaria for suture diastasis.

\section{Acknowledgments}

We thank Allison Krug, MPH, for the thoughtful editing of this document.

\section{References}

1. Tang N, Stein J, Hsia RY, et al. Trends and characteristics of US emergency department visits, 1997-2007. JAMA;304:664-70

2. Krauss BS, Harakal T, Fleisher GR. The spectrum and frequency of illness presenting to a pediatric emergency department. Pediatr Emerg Care 1991; 7:67-71

3. American College of Radiology. ACR Appropriateness Criteria. Head Truma. 2008. Availableathttp://www.acr.org/SecondaryMainMenu Categories/quality_ safety/app_criteria/pdf/ExpertPanelonNeurologicImaging/HeadTraumaDoc5. aspx. Accessed January 5, 2011

4. American College of Radiology. ACR Appropriateness Criteria. Head TraumaPediatric. 2008. Available at http://www.acr.org/SecondaryMainMenuCategories/ quality_safety/app_criteria/pdf/ExpertPanelonPediatricImaging/SuspectedPhysi calAbuseChildDoc9.aspx. Accessed January 5, 2011.

5. Frush DP, O'Hara SM, Kliewer MA. Pediatric imaging perspective: acute head trauma-is skull radiography useful? J Pediatr 1998;132:553-54

6. Atabaki SM. Pediatric head injury. Pediatr Rev 2007;28:215-24

7. Henderson S, Sherman L. The Roentgen anatomy of the skull in the newborn infant. Radiology 1946;46:107-18

8. Erasmie U, Ringertz H. Normal width of cranial sutures in the neonate and infant. An objective method of assessment. Acta Radiol Diagn (Stockh) 1976;17:565-72

9. Soboleski D, McCloskey D, Mussari B, et al. Sonography of normal cranial sutures. AJR Am J Roentgenol 1997;168:819-21

10. Furuya Y, Edwards MS, Alpers CE, et al. Computerized tomography of cranial sutures. Part 1: comparison of suture anatomy in children and adults. J Neurosurg 1984;61:53-58

11. Fernando S, Obaldo RE, Walsh IR, et al. Neuroimaging of nonaccidental head trauma: pitfalls and controversies. Pediatr Radiol 2008;38:827-38

12. Meservy CJ, Towbin R, McLaurin RL, et al. Radiographic characteristics of skull fractures resulting from child abuse. AJR Am J Roentgenol 1987;149: 173-75

13. Stokes NJ, Cremin BJ. The skull vault in neonates and infants. Australas Radiol 1974;18:275-82

14. Swischuk LE. The normal newborn skull. Semin Roentgenol 1974;9:101-13

15. Cohen MM, Jr. Sutural biology and the correlates of craniosynostosis. Am J Med Genet 1993;47:581-616

16. Lynnerup N, Jacobsen JC. Brief communication: age and fractal dimensions of human sagittal and coronal sutures. Am J Phys Anthropol 2003;121:332-36

17. Key C, Aiello L, Molleson T. Cranial suture closure and its implications for age estimation. Int J Osteoarchaeol 1994;4:193-208

18. Hershkovitz I, Latimer B, Dutour O, et al. Why do we fail in aging the skull from the sagittal suture? Am J Phys Anthropol 1997;103:393-99

19. Herring SW. Sutures-a tool in functional cranial analysis. Acta Anat (Basel) 1972;83:222-47

20. Meindl RS, Lovejoy CO. Ectocranial suture closure: a revised method for the determination of skeletal age at death based on the lateral-anterior sutures. Am J Phys Anthropol 1985;68:57-66 